\title{
The British Rhinological Society Multidisciplinary Consensus on the Hospital Management of Epistaxis
}

INTEGRATE: (Steering Committee: M. Ellis, A. Hall, J. Hardman, N. Mehta, P.Nankiwell, N.Sharma, M.E Smith, R Williams)

British Rhinological Society Epistaxis Consensus Committee: (W. Adams; S. Carrie; R.Cathcart; P. Chatrath; C. Hopkins; R. Lenthall; J.Mainwaring; P. Nix; T. Nokes; C. Philpott; A. Reuben; R. Salib; P. Sura; A. Sutton; V. Ward; P. White)

Conflicts of interest:

None declared

Key words:

Epistaxis; assessment; cautery; packing; haematology; surgery.

Funding:

This national audit was funded by ENTUK. The funding body had no influence over content. 
Authorship details

Dr William Adams

Consultant Neuroradiologist

Plymouth Hospitals NHS Trust

Mr Sean Carrie

Consultant Rhinologist/ENT Surgeon

Freeman Hospital, Newcastle

Mr Russell Cathcart

Consultant Rhinologist/ENT Surgeon

Jersey General Hospital

Mr Paul Chatrath

Consultant Rhinologist/ENT Surgeon

Charing Cross Hospital / Imperial Healthcare NHS Trust

Mr Matthew Ellis

Specialist Registrar in Otolaryngology

Freeman Hospital, Newcastle

Mr Andrew Hall

Specialist Registrar in Otolaryngology

Royal National Throat, Nose and Ear Hospital, London

Mr John Hardiman

Specialist Registrar in Otolaryngology

St Mary's Hospital, London

Professor Claire Hopkins

Consultant ENT Surgeon \& Rhinologist

Guys and St Thomas Hospital, London

Mr Robert Lenthall

Consultant Neuroradiologist

Nottingham University Hospital

Dr Jason Mainwaring

Consultant Haematologist

Royal Bournemouth and Christchurch Hospitals

Mr Nish Mehta

Specialist Registrar in Otolaryngology

Royal National Throat, Nose and Ear Hospital, London

Mr Paul Nankiwell 
Consultant ENT Surgery

University Hospital Birmingham

Dr Timothy J.C. Nokes

Consultant Haematologist

Derriford Hospital, Plymouth

Mr Paul Nix

Consultant in Rhinology and Anterior Skull Base surgery

Leeds General Infirmary

Professor Carl Philpott

Consultant ENT Surgeon \& Rhinologist

James Paget University Hospital

Dr Adam Reuben FRCEM

Consultant in Emergency Medicine

Royal Devon and Exeter Hospital

Mr Rami J Salib

Associate Professor of Rhinology

Consultant ENT Surgeon- University Hospital Southampton

Mr Neil Sharma

Specialist Registrar in Otolaryngology

University Hospital Birmingham

Mr Matthew E. Smith

Specialist Registrar in Otolaryngology

Addenbrookes Hospital, Cambridge

Mr Priyesh Sura

Consultant in Emergency Medicine

Kings College Hospital, London

Andrew Sutton

Associate Professor in Health Economics

Leeds Institute of Health Sciences

Miss Victoria MM Ward

Consultant Otorhinolaryngologist

Mid Yorks NHS Trust

Mr Paul White

Consultant Rhinologist and ENT Surgeon

Ninewells Hospital, Dundee 
Mr Richard Williams

Specialist Registrar in Otolaryngology

Institute of Naval Medicine, Plymouth

Corresponding Author:

Mr Richard Williams

Institute of Naval Medicine,

Crescent Rd,

Alverstoke,

Gosport.

PO12 2DL

Richard.williams8@nhs.net 


\section{INTRODUCTION}

Epistaxis is the most common acute presentation to ENT services in the UK. In the financial year 2009-10, 23,723 epistaxis-related admissions were recorded in the National Health Service Hospital Episode Statistics for England and Wales ${ }^{1}$. Despite this high incidence, there are currently no nationally accepted guidelines for its management ${ }^{2}$. A recent multi-centred pilot audit ${ }^{3}$ undertaken by INTEGRATE (The National ENT Trainee Research Network) demonstrated a wide variation in practice. The goal of this multidisciplinary consensus guideline was to develop agreed evidenced-based recommendations for the management of this common condition. This guideline was then utilized as the gold-standard for the subsequent national audit of epistaxis management ${ }^{4}$.

\section{METHODS}

Recommendations were developed using an AGREE II framework ${ }^{5}$, a method successfully utilized in the 2009 Hereditary Haemorrhagic Telangiectasia guidelines $^{6}$. Consensus member disagreement was managed using an adaptation of the method utilized within RAND/UCLA appropriateness studies ${ }^{7}$. The use of established guideline generation methodology sought to provide rigour in development, despite an expected paucity in high-level evidence.

\section{Scope and Purpose}

Representatives from the ENT-UK Clinical Audit and Practice Advisory Group (CAPAG) and the British Rhinological Society (BRS) approached INTEGRATE highlighting the requirement for nationally accepted standards of care in epistaxis. This guideline seeks to recommend evidence-based best practice for the hospital management of epistaxis of all severity in adults, within the 
context of commonly associated comorbidities known to affect outcome. We exclude guidance on paediatric epistaxis, hereditary haemorrhagic telangiectasia and other specific haematological conditions.

\section{Stakeholder Involvement}

The organising committee was composed of 7 junior clinicians including a nominated chair and 2 executive senior members. The organising committee were responsible for developing the consensus methodology and co-ordinating a multi-faceted systematic review of the relevant literature. The consensus panel was composed of patients, ENT surgeons and representative experts from allied specialties involved in the management of epistaxis from across the UK. An open invite was extended to all consultant members of BRS and ENTUK to participate in the consensus panel as ENT representatives. Allied specialty consultants and patient representatives were invited individually following identification by the steering committee as appropriate experts in their fields. Individuals from health economics, emergency medicine, haematology, interventional radiology, general ENT and rhinology all contributed to the guidelines.

\section{Rigour of Development}

For the purposes of this consensus, the management of epistaxis was divided into 5 domains (initial assessment, cautery, intranasal agents, haematological factors, surgery and radiological intervention). Each domain was assigned coauthors from locations throughout the UK. Within the domains, a total of 15 systematic reviews ${ }^{8-12}$ were conducted, with the support of Cambridge and Exeter Universities plus the Defence Military Library. A robust yet pragmatic 
methodology was followed including validated assessment of bias ${ }^{13-14}$, capturing all relevant published evidence of level 3 and above.

The data synthesis and full-text included articles were made available to the consensus panel members, prior to domain co-authors presenting their findings at a guidelines conference held in Leeds on the $19^{\text {th }}$ May 2016. A consensus panel discussion was held following each domain presentation, facilitated by the chair of the consensus panel, seeking to generate management recommendations. These discussions were digitally recorded and converted to a written consensus matrix by the steering committee. Each recommendation was then linked with the level of evidence ${ }^{15}$ supporting each statement and a GRADE score ${ }^{16}$ explaining the strength of recommendation in context of the evidence plus the perceived harm and benefit. The draft matrix was then returned to the consensus panel electronically for 2 separate rounds of comments and subsequent adjustment.

Following final consensus matrix adjustment, the level of consensus agreement was then sought by requesting consensus panel members to independently assign an agreement rating from 0-10 for each recommendation. 0 represented complete disagreement with the statement and 10 absolute agreement. Panel members were asked to abstain from comment when the specific recommendation was felt to be outside their clinical remit.

Statements achieving a median rating of $<7$ were excluded from the consensus matrix. Disagreement was defined as statements achieving a median rating $\geq 7$ but with individual ratings of $<4$. In these cases, outlying panel members were given the opportunity to revise their score if desired. All retained statements were reported with their median consensus agreement rating, range of ratings and an asterisk annotated where ratings were revised following disagreement. 
It is anticipated that the consensus recommendations will be updated following completion of each cycle of the national audit of epistaxis management ${ }^{4}$.

\section{RECOMMENDATIONS}

Initial Assessment (fig. 1)

Despite low and very low quality of evidence, a number of strong recommendations were made. This was achieved due the lack of perceived risk of recommendation versus consensus agreed benefit. Recommendations centred round the use of a structured $A B C$ approach and the recording of key comorbidities with evidence available to support their impact on patient outcome. Very low quality or absence of evidence limited the strength of recommendation regarding the use of well-established first aid methods as well as specific statements regarding the clinical examination methods and investigation of patients presenting with epistaxis. Despite these limitations there were consistently high agreement rating levels with minimal disagreement in accepted statements.

\section{Cautery (fig. 2)}

Low and very low quality evidence again limited the strength of recommendations made regarding intranasal cautery (fig. 3). Strong recommendations were made supporting cautery as a first line treatment in all patients, but that cautery should be targeted at identified points of bleeding. Weak recommendations were made regarding the need for specific cautery training, the use of topical vasoconstrictors, electrocautery in preference to silver nitrate and advanced clinical examinations when a bleeding point is not 
initially identified with anterior rhinoscopy. There were high median agreement ratings for all statements with no disagreement.

\section{Intranasal Agents (fig.3)}

This domain was unusually supported, in places, by moderate and strong quality evidence. This allowed the strong recommendation of non-dissolvable anterior nasal packs as an effective haemostatic intervention in stipulated clinical scenarios when placed by individuals specifically trained in their use. Consensus opinion strongly supported the use of targeted cautery following removal of non-dissolvable packs despite no supporting evidence. This was based on a perceived significant benefit balanced against any potential harm or cost. The consensus panel weakly recommended the use of Rapid Rhino packs over Merocel as the non-dissolvable pack of choice, as well as recommendation regarding the length of time a pack should remain in-situ and how long patients should be observed following pack removal. Despite median agreement ratings largely between 8 and 9.5 there were several instances of disagreement.

Recommendations regarding the use of dissolvable packs and haemostatic agents were limited by a paucity of quality evidence, the diversity of available products and a lack of clarity regarding where in the treatment of epistaxis these products should be employed. 3 of the 4 recommendations received low agreement ratings of 7 or 7.5 and there was 1 instance of disagreement.

\section{Anti-thrombotic therapy (fig. 4) and haematological factors (fig. 5)}

Despite no epistaxis-specific supporting evidence, several weak recommendations were made regarding the management of warfarin, direct 
oral anticoagulants (DOAC) and heparin. These centred around the extrapolation of generic national guidelines and maintaining a low threshold for seeking case-specific haematological advice. Despite weak strength of recommendations there was universally high levels of median agreement rating with no instances of disagreement.

Similarly, there was no evidence to recommend an epistaxis-specific treatment strategy for the management of ongoing antiplatelet therapy. Consensus opinion recommended the continuation of such agents in uncomplicated cases and the involvement of allied specialties in complex or refractory cases. Levels of agreement were high without disagreement.

Transfusion strategies for epistaxis were again based on evidence unrelated to the condition. Despite this, a number of strong recommendations were made for the use of elements of The British Committee for Standards in Haematology guidelines for the management of major haemorrhage ${ }^{17}$. Median agreement ratings were 10 for recommendations, with 1 instance of disagreement.

Tranexamic acid (TXA) use in epistaxis benefited from moderate quality evidence, however, with inconsistent findings. As a result, weak recommendations for its use were made with median rater agreement of 7 and 8 with disagreement in both epistaxis specific statements. National guidelines regarding the use of TXA in defined major haemorrhage were strongly recommended and received a median agreement rating of 10 without disagreement.

Surgery and Radiological Intervention (fig. 6) 
Weak strength recommendations were made regarding the role of surgical and radiological intervention in epistaxis. This was limited by the lack of quality evidence in this area. Despite this, consensus agreement was high for the identified clinical scenarios requiring treatment escalation and that surgery should be preferred to radiological intervention. However, interventional radiologists were outnumbered by ENT surgeons on the consensus panel which may have biased the median agreement rating.

\section{CONCLUSIONS}

These consensus recommendations are based on a wide-ranging review of the relevant literature and established and rigorous methods of guideline generation. As a result, it is envisaged that the findings of this document should be of use to all hospital clinicians managing acute epistaxis. Readers should remain cognisant that the evidence identified to support this guideline is largely of low or very low quality and expert consensus opinion was often required to reach recommendations. Whilst this should not undermine the utility of the document, caution should be use when implementing these findings. These recommendations will continue to be updated as new evidence comes to light.

\section{EDITORIAL INDEPENDENCE}

The systematic reviews and consensus process were funded by ENTUK. The funding body did not influence the content of this guideline.

All consensus panel members were asked to declare with details any competing interests. Competing interests declared were: 
$A R$ - Was granted a Research for Patient Benefit grant to investigate the use of topical tranexamic acid (TXA) in epistaxis. To avoid any external concerns regarding a potential conflict of interest, $A R^{\prime}$ s agreement ratings were not included in recommendations regarding the use of TXA in epistaxis. 


\section{REFERENCES}

${ }^{1} \mathrm{NHS}$ Hospital Episode Statistics in England and Wales 2011-2012. In:

http://www.hesonline.nhs.uk [16 ${ }^{\text {th }}$ June 2017$\}$

${ }^{2}$ Hall, A., Blanchard, H., Chatrath, P., Hopkins, C. (2015) Epistaxis management: 'A MultiCentre Audit in England: Is there a case for a national review of practice? Journal of Laryngology \& Otology. 30:1-4

${ }^{3}$ Mehta N, Williams RJ, Smith ME, Hall A, Hardman JC, Cheung L, Ellis MP, Fussey JM, Lakhani R, McLaren O, Nankivell PC, Sharma N, Yeung W, Carrie S, Hopkins C. (2017) Can trainees design and deliver a national audit of epistaxis management? A pilot of a secure web-based audit tool and research trainee collaboratives. J Laryngol Otol. 131(6):518-522

4 INTEGRATE: Epistaxis 2016: National Audit of Management (SUBMITTED TO JLO IN SAME ISSUE)

${ }^{5}$ Brouwers MC, Kho ME, Browman GP, et al. AGREE II: advancing guideline development, reporting and evaluation in health care. CMAJ: Canadian Medical Association Journal. $2010 ; 182(18)$

${ }^{6}$ Faughnan ME, Palda VA, Garcia-Tsao G, et al International guidelines for the diagnosis and management of hereditary haemorrhagic telangiectasia Journal of Medical Genetics 2011;48:73-87. 
${ }^{7}$ Fitch K, Bernstein SJ, Aguilar MD et al. The RAND/UCLA Appropriateness Method User's Manual. Santa Monica, CA: RAND Corporation; 2001.

${ }^{8}$ Mcleod R.W.J, Price, A., Williams, R.J., Smith, M.E., Smith M., Owens, D. Intranasal cautery for the management of adult epistaxis: A systematic review (SUBMITTED TO JLO IN SAME ISSUE)

${ }^{9}$ Williams, A., Biffen A., Pilkington, N., Arrick L., Williams, R.J., Smith, M.E., Smith, M., Birchall J. Haematological factors in the management of adult epistaxis: A systematic review (SUBMITTED TO JLO IN SAME ISSUE)

${ }^{10}$ Iqbal, I., Huw Jones, G., Dawe, N., Mamais, C., Smith, M.E., Williams, R.J., Kuhn, I., Carrie, S. Intranasal packs and haemostatic agents for the management of adult epistaxis: A systematic review (SUBMITTED TO JLO IN SAME ISSUE)

${ }^{11}$ Khan, M., Conroy, K., Ubayasiri, K., Constable, J., Smith, M.E., Williams, R.J., Kuhn, I., Smith, M., Philpott, C. First aid and initial assessment for epistaxis, and patient factors affecting outcome: A systematic review (SUBMITTED TO JLO IN SAME ISSUE)

${ }^{12}$ Swords, C., Patel, A., Smith, M.E., Williams, R.J., Kuhn, I., Hopkins, C. Surgical and interventional radiological management of adult epistaxis: A systematic review (SUBMITTED TO JLO IN SAME ISSUE) 
${ }^{13}$ Higgins JPT, Altman DG, Gøtzsche PC, et al. The Cochrane Collaboration's tool for assessing risk of bias in randomised trials. The BMJ. 2011;343:d5928. doi:10.1136/bmj.d5928.

${ }^{14}$ Slim, K., Nini, E., Forestier, D., Kwiatkowski, F., Panis, Y. and Chipponi, J. (2003), Methodological index for non-randomized studies (MINORS): development and validation of a new instrument. ANZ Journal of Surgery, 73: 712-716.

${ }^{15}$ Howick, J., Chalmers, I., Glasziou, P. et al The 2011 Oxford CEBM Levels of Evidence (Introductory Document) Oxford Centre for Evidence Based Medicine http://www.cebm.net/index.aspx?o=5653 (accessed 16 June 2017)

${ }^{16}$ Guyatt, G.H., Oxman, A.D., Vist, G.E., Kunz, R., Falck-Ytter, Y., Alonso-Coello, P. et al. GRADE: an emerging consensus on rating quality of evidence and strength of recommendations. BMJ. 2008; 336: 924-926

${ }^{17}$ Hunt, B. J., Allard, S., Keeling, D., Norfolk, D., Stanworth, S. J., Pendry, K. and the British Committee for Standards in Haematology (2015), A practical guideline for the haematological management of major haemorrhage. Br J Haematol, 170: 788-803. 